\title{
A contribuição das metodologias ativas para a prática pedagógica dos professores universitários ${ }^{1}$
}

\author{
Caroline Elizabel Blaszkoi \\ Universidade Estadual do Paraná, União da Vitória, PR, Brasil \\ Ana Lúcia de Araújo Claroii \\ Pontifícia Universidade Católica do Paraná, Curitiba, PR, Brasil \\ Nájela Tavares Ujiie \\ Universidade Estadual do Paraná, Paranavaí, PR, Brasil
}

\begin{abstract}
Resumo
Este trabalho se origina da pesquisa realizada com professores universitários que fazem parte do grupo de pesquisa que investiga os Paradigmas Educacionais e Formação de Professores, vinculado à Linha de Pesquisa: Teoria e Prática Pedagógica na Formação de Professores em um Programa de Pós-Graduação em Educação de uma universidade de grande porte na cidade de Curitiba, Paraná. Objetivou-se compreender a contribuição das metodologias ativas para a prática docente dos professores universitários. A metodologia utilizada pauta-se em uma abordagem qualitativa do tipo estudo de caso, que prima por interpretar, de modo analítico, os dados captados no decurso da pesquisa. A partir das análises dos dados, foi possível verificar que a proposta das metodologias ativas pode se constituir como uma proposta de ensino numa visão complexa ou holística, que possibilita uma aprendizagem significativa para os alunos, protagonistas da construção do conhecimento de forma autônoma, crítica, reflexiva e participativa.
\end{abstract}

Palavras-chave

Ensino superior. Metodologias ativas. Aprendizagem. Prática pedagógica.

The contribution of active methodologies to the pedagogical practice of university professors

\begin{abstract}
This work originates from the research carried out with university professors who are part of the research group that investigates Educational Paradigms and Teacher Training, linked to the Research Line: Pedagogical Theory and Practice in Teacher Education in a Graduate Program in Education from a large university in the city of Curitiba, Paraná. The objective was to understand the contribution of active methodologies to the teaching practice of university professors. The methodology used is based on a qualitative approach of the case study type that aims to interpret, in an analytical way, the data captured in the course of the research. From the data analysis, it was possible to verify
\end{abstract}

1 A pesquisa foi desenvolvida conforme a Resolução 466/12 do Conselho Nacional de Saúde, na qual foi assinado o Termo de Consentimento Livre esclarecido pelos sujeitos da pesquisa.

Educ. Form., Fortaleza, v. 6, n. 2, e3908, maio/ago. 2021

DOI: https://doi.org/10.25053/redufor.v6i2.3908

https://revistas.uece.br/index.php/redufor/index ISSN: 2448-3583 
that the proposal of the active methodologies can be constituted as a teaching proposal in a complex or holistic view, which enables a meaningful learning for the students, protagonists of the construction of knowledge in an autonomous, critical, reflective, and participatory manner.

\title{
Keywords
}

Higher education. Active methodologies. Learning. Pedagogical practice.

\section{La contribución de las metodologías activas a la práctica pedagógica de los docentes universitarios}

\begin{abstract}
Resumen
Este trabajo fue realizado a partir de la investigación hecha con docentes universitarios que forman parte del grupo de investigación sobre Paradigmas Educativos y Formación de Docentes, vinculado a la Línea de Investigación: Teoría y Práctica Pedagógica en la Formación de Docentes en un Programa de Posgrado en Educación de una gran universidad de la ciudad de Curitiba, Paraná. El objetivo consiste en comprender la contribución de las metodologías activas a la práctica docente de los profesores universitarios. La metodología utilizada se basa en un estudio de caso cualitativo, que se destaca por interpretar de manera analítica los datos obtenidos durante la investigación. A partir del análisis de los datos, se pudo comprobar que la propuesta de las metodologías activas puede constituir una propuesta de enseñanza desde una mirada compleja u holística, que posibilita un aprendizaje significativo para los alumnos, protagonistas de la construcción del conocimiento de forma autónoma, crítica, reflexiva y participativa.
\end{abstract}

Palabras clave

Enseñanza superior. Metodologías activas. Aprendizaje. Prácticas pedagógicas.

\section{Introdução}

A prática pedagógica dos docentes universitários constitui-se objeto de pesquisa de diversos estudiosos, como Behrens (2011), Masetto (2011), Moran (2018), Veiga (2009), entre outros. Cada dia surgem novos questionamentos sobre o fazer pedagógico, sobre práticas inovadoras e dinâmicas que podem trazer contribuições para ressignificar a prática dos professores.

Assim, por meio das mudanças que vêm ocorrendo no âmbito da educação, todo dia surgem novos desafios a serem superados pelos professores, ou seja, há uma exigência de mudança do paradigma conservador. Esse enfrentamento reflete na prática pedagógica deles, que também requer mudança por uma postura crítica, reflexiva e transformadora, abrangendo as metodologias de ensino e as práticas educativas. 
Moran (2013, p. 83) argumenta acerca da importância da prática docente reflexiva buscando potencializar o processo de ensino, uma vez que a aprendizagem deve "[...] ser significativa, desafiadora, problematizadora e instigante, a ponto de mobilizar o aluno e o grupo a buscar soluções possíveis para serem discutidas e concretizadas à luz de referências teórico-práticas".

Frente ao exposto, a formação do aluno universitário deve ser pensada numa perspectiva mais ampla, em coaduno com o paradigma da complexidade, compreendendo-o como um ser em sua totalidade, que envolve a dimensão social, afetiva, cultural, ética e espiritual. Sendo assim, conceber uma visão complexa "[...] implica pensar coletivamente, uns dependendo do sucesso dos outros, das parcerias, do trabalho coletivo" (MORAN, 2013, p. 88).

Desse modo, pode-se inferir que tal postura traz implicações à ação docente, que pode ter ancoragem nas metodologias ativas. Nessa perspectiva, busca-se analisar a contribuição do uso das metodologias ativas como estratégia de mediação junto à prática pedagógica de seis professores universitários que tomaram parte na pesquisa.

O referencial teórico foi embasado nos estudos de Behrens $(2008,2011)$, Masetto (2006), Moran (2018), Zabala (2002), entre outros. O artigo é apresentado da seguinte maneira: primeiramente se apresenta uma reflexão sobre educação no contexto atual, sobre a prática pedagógica e sobre a importância das metodologias ativas; na sequência, discute-se a abordagem metodológica e tecem-se as análises do âmago da pesquisa, via concepções dos docentes universitários, relacionadas ao trabalho com metodologias ativas em nível superior.

\section{A educação no contexto da contemporaneidade, a prática pedagógica e a importância das metodologias ativas}

As instituições de ensino superior são importantes para a produção do conhecimento, além de ser um espaço de discussões, de debates e de reflexões - são um lócus de pesquisa, de investigação em torno do conhecimento científico. Nesse sentido, a prática de formação dos professores precisa ser pensada a partir da complexidade, como: 
[...] uma prática pedagógica num paradigma emergente que alicerça ensino com pesquisa, numa visão holística com uma abordagem progressista, o que, sem dúvida, trará para a universidade uma produção de conhecimento significativa e relevante que propicie a formação de cidadãos éticos e competentes para construir uma sociedade mais justa e igualitária. (BEHRENS, 2013, p. 135).

Diante disso e das transformações que vieram acontecendo nas últimas décadas, observa-se a necessidade de repensar os paradigmas vigentes na educação. $\mathrm{Na}$ perspectiva de Zabala (2002), a função do ensino pauta-se num processo de compreensão e intervenção da realidade: isso implica ensinar a partir do paradigma da complexidade.

Pensar a educação numa visão mais ampla exige a mudança paradigmática, que, nesse momento, aponta para a teoria da complexidade proposta por Morin (2001). O paradigma da complexidade permite que se compreenda a incompletude do ser humano; por essa razão, pode auxiliar a entender o ser humano em sua inteireza, uma vez que ele vai se constituindo nessas teias de relações.

Para Capra (2006, p. 25), a adesão ao novo paradigma representa a ruptura com o conservadorismo e a ampliação do horizonte "[...] que concebe o mundo como um todo integrado, e não como uma coleção de partes dissociadas. [...] que reconhece a interdependência fundamental de todos os fenômenos [...]".

Yus (2002, p. 21) corrobora o pensamento de Capra (2006) ao afirmar que a educação, numa perspectiva holística ou complexa, centra-se "[...] no crescimento de todas as potencialidades: intelectual, emocional, social, física, artística, estética, criativa, intuitiva e espiritual". Portanto, é importante destacar que, nesse processo educativo, o aprendiz é um ser que aprende em plenitude, por meio da integração entre mente, corpo, sentimentos, interesses e imaginação.

A educação é um processo de emancipação e transformação do ser humano. Nesse sentido, Moraes (2004) ressalta o papel do professor no processo formativo pleno dos acadêmicos: suas ações são essenciais, pois contribuem para a formação não só profissional, mas, sobretudo, humana.

Ao refletir sobre a prática pedagógica, é imprescindível compreender que, para atuar como professor, faz-se necessário "[...] ampliar o nível de percepção para compreender e enfrentar os novos desafios impostos à docência pelo mundo globalizado e mundializado" (BEHRENS; PRIGOL, 2019, p. 65). 
Assim, formar professores para atuar nas universidades requer primeiramente entender a relevância: "[...] do papel da docência; propiciar a eles uma profundidade científico-pedagógica que os capacite a enfrentar questões fundamentais da universidade como instituição social - uma prática social que contempla ideias de formação, reflexão, crítica" (VEIGA, 2009, p. 43). Na dimensão apresentada, a autora ressalta a importância de romper com a visão conservadora e alinhar a prática pedagógica à intencionalidade educativa, que integra o ensinar, o aprender, o pesquisar e o avaliar como atos educativos e formativos: complexos.

Em se tratando do desenvolvimento profissional, Mororó (2017, p. 42) aponta que "[...] o professor precisa apreender em sua consciência a relação entre o objetivo da ação educativa e o motivo da atividade educativa na qual está envolvido, ou seja, o motivo da sua prática pedagógica”. Corroborando essa ideia, Mezzaroba e Carriquiriborde (2020, p. 17) explicam que, ao entendermos as práticas educativas como "[...] ações pensadas, refletidas e experimentadas pelos docentes como intelectuais transformadores, então sabemos a necessidade de combinar a reflexão e a ação, ou seja, teoria e prática, com um olhar para uma educação que problematize a realidade [...]".

Neste enfoque, Ujiie (2020) debate a ação formativa e educativa que alinha pesquisa e ensino, considerando a formação inicial e continuada de professores para dar conta da realidade. Nesse sentido, é importante compreender que "[...] a universidade, antes de ser uma instituição de ensino, deve ser uma instância de aprendizagem" (BEHRENS, 2006, p. 451). Ou seja, é papel das universidades garantir a aprendizagem e a formação e promover momentos de reflexão sobre a produção do conhecimento.

Ressalta-se que a prática pedagógica inovadora possibilita que professores e alunos possam produzir, questionar, construir e criar conhecimentos. Além disso, favorece a construção de conhecimentos e experiências juntamente aos seus pares. Nessa seara fértil, é importante compreender a relevância do papel profissional do professor em uma comunidade, na sociedade e no mundo, uma vez que ele necessita "[...] refletir e realinhar sua prática pedagógica no sentido de criar possibilidades para instigar a aprendizagem do aluno. O foco passa da ênfase do ensinar para a ênfase do aprender" (BEHRENS, 2013, p. 78).

Assim, Masetto (1998) destaca a importância da relação professor/aluno no processo de aprendizagem, sendo o papel do professor orientar, motivar e incentivar o 
desenvolvimento das atividades. Para isso, é necessário que esse profissional desenvolva ação ativa, uma atitude de parceria e corresponsabilidade com os alunos, que planejem o curso juntos, usando técnicas em sala de aula que facilitem a participação e considerando os discentes como adultos que podem se corresponsabilizar por seu período de formação profissional.

Neste enfoque, o educador é entendido segundo Junges, Ketzer e Oliveira (2018, p. 94) "[...] como todo aquele que atua profissionalmente com o ensino e a aprendizagem, seja qual for o nível, que procura um meio para encaminhar o educando em uma aprendizagem mais significativa".

Outro aspecto importante que Masetto (1998) enfatiza diz respeito às exigências da docência em nível de ensino superior, dentre as quais se destacam: a) domínio conceitual de uma determinada área de conhecimento; b) domínio pedagógico - a maneira de ensinar e de relacioná-la com o conhecimento e os alunos; c) domínio político e social - do seu ser e estar na universidade e no mundo como cidadão histórico e de direitos.

O contexto educacional demanda mudanças na prática educativa dos docentes, pois o mundo é dinâmico, assim como a educação prevalecente na contemporaneidade deve ser ativa. De tal modo, "[...] a aprendizagem por questionamento e experimentação é mais relevante para uma compreensão mais ampla e profunda" (BACICH; MORAN, 2018, p. 2) da realidade e da educação.

Nesse sentido, Behrens (2014, p. 97) aponta que a metodologia que integra ensino e pesquisa proporciona a reorganização do trabalho docente, sendo que "[...] o aprender a aprender coloca o professor e o aluno como agentes de investigação, para tanto, superam as perguntas com respostas prontas e sugerem a proposição de problematizações para as quais é preciso buscar as possíveis respostas". Assim, no cenário educacional, entra em voga a questão das metodologias ativas, compreendidas "[...] como estratégias de ensino centradas na participação efetiva dos estudantes na construção do processo de aprendizagem, de forma flexível, interligada e híbrida" (BACICH; MORAN, 2018, p. 2).

A partir das metodologias ativas, o estudante se constitui como um ser que interage ativamente e constrói conhecimento de forma individual e coletiva. Nesse sentido, o professor tem papel ímpar em estimular e despertar a curiosidade dos alunos, tornando-os protagonistas de suas aprendizagens, incentivando-os para que se tornem 
pesquisadores, descobridores de seus potenciais, por meio de uma aprendizagem que deve acontecer não só de forma individual, mas também em processos coletivos, em parceria com seus colegas e professores.

$\mathrm{Na}$ visão de Valente $(2018$, p. 27 ), as metodologias ativas "[...] constituem alternativas pedagógicas que colocam o foco do processo de ensino e de aprendizagem no aprendiz, envolvendo-o na aprendizagem por descoberta, investigação ou resolução de problemas". Para o autor, tal proposta contrapõe a abordagem tradicional, exige uma nova postura do professor, uma prática pedagógica que se volte para as demandas do educando e para a realidade imanente. Dessa forma, as metodologias ativas:

[...] procuram criar situações de aprendizagem nas quais os aprendizes possam fazer coisas, pensar e conceituar o que fazem e construir conhecimentos sobre os conteúdos envolvidos nas atividades que realizam, bem como desenvolver a capacidade crítica, refletir sobre as práticas realizadas, fornecer e receber feedback, aprender a interagir com colegas e professor, além de explorar atitudes e valores pessoais. (VALENTE, 2018, p. 28).

As metodologias ativas são um caminho essencial na contemporaneidade, tendo em vista que tal proposta coloca o foco no sujeito: o aluno constitui-se como protagonista de suas aprendizagens. $O$ indivíduo assume compromisso e responsabilidade com sua educação e formação, uma postura mais participativa, investigativa, que possibilite a construção do conhecimento, no âmbito universitário e na sua constituição profissional. O professor é "[...] mediador, consultor do aprendiz. E a sala de aula passa a ser o local onde o aprendiz tem a presença do professor e dos colegas para auxiliá-lo na resolução de suas tarefas, na troca de ideias e na significação da informação" (VALENTE, 2018, p. 42).

As metodologias ativas na ação prática demandam:

[...] transformar objetivos de ensino do educador em expectativas de aprendizagem para os estudantes. As metodologias ativas de aprendizagem devem propiciar aos educadores recursos e práticas didáticas que permitam 0 'ensinar' diante de cenários, ambientes e clientela - estudantes e comunidades com necessidades diversificadas e o 'educar' para a compreensão do mundo em que vivemos. (SENNA et al., 2018, p. 223).

Frente ao exposto, pode-se inferir que as metodologias ativas se constituem como uma proposta de ensino que possibilita aprendizagem significativa, reflexiva e participativa. Dessa forma, as metodologias ativas provocam uma transformação na 
prática pedagógica em relação à mudança da postura de transmissor para mediador e orientador das aprendizagens dos alunos.

As metodologias ativas são molas propulsoras de aprendizagem significativa, fortalecedoras da formação do cidadão e da autonomia humana, sendo contributivas, de acordo com Ujiie (2020), na formação de professores e alunos, sujeitos de direitos e conscientes de seu papel social e transformador perante a sociedade.

\section{Percurso metodológico e achados da pesquisa}

A opção metodológica desta pesquisa pauta-se em uma abordagem qualitativa envolvendo estudo de caso, na qual os dados coletados são descritivos, que, no caso da investigação em pauta, foram captados via entrevista semiestruturada com membros de um grupo de pesquisa e merecem análise em seus aspectos relativos à qualidade. Tais dados são normalmente recolhidos nos ambientes naturais, e os investigadores analisam os dados coletados em "[...] toda sua riqueza, respeitando, tanto quanto possível, a forma em que estes foram registrados ou transcritos" (BOGDAN; BIKLEN, 1994, p. 48). Esse procedimento é de suma importância para o investigador compreender o problema em estudo.

Estudo de caso, de acordo com Ujiie et al. (2016), é uma modalidade investigativa que possibilita análise interpretativa e subjetiva dos dados, que podem ser captados por observações, entrevistas, anamneses e conversas informais com os participantes da pesquisa. $O$ estudo de caso representa uma experiência vicária que, embora singular, possibilita associações a outros contextos e realidades.

Lüdke e André (2013) definem o estudo de um caso como uma modalidade que utiliza fontes variadas na captação de dados, visa à descoberta, enfatiza a interpretação do contexto, faz uso de linguagem acessível, geralmente relatos escritos, citações, exemplos e descrições.

Em relação aos participantes deste estudo, foram convidados os participantes do seminário de aprofundamento que fez parte da linha de Teoria e Prática Pedagógica na Formação de Professores, que realizou 15 encontros de cerca de três horas, perfazendo 45 horas, e debateu práticas inovadoras e as metodologias ativas. Do universo de 15 participantes, fizeram adesão por livre escolha seis professores universitários com 
formações diferenciadas, sendo três da área de Matemática e três da área de Pedagogia, que já utilizavam as metodologias ativas em sua realidade de pertença.

A coleta de dados teve por foco suas experiências particulares, buscando captar e analisar suas concepções relacionadas às metodologias ativas na educação superior. Visando esclarecer a problemática investigativa, foi lançada a seguinte questão: "Como as metodologias ativas de aprendizagem podem contribuir para melhorar a prática docente dos professores universitários?".

Para a realização do estudo, ao final do seminário foi realizada uma entrevista semiestruturada com os participantes com experiência no ensino superior e que desejassem fazer adesão à pesquisa. A entrevista apresentou cinco questões - uma fechada e quatro abertas. Seguindo os imperativos éticos da pesquisa em educação, estes preencheram o Termo de Consentimento Livre e Esclarecido. Para salvaguardar o anonimato dos participantes, eles foram denominados por números - P1 a P6.

Para os professores universitários partícipes do estudo, as metodologias ativas desempenham um papel importante na aprendizagem dos acadêmicos, como é possível constatar em alguns dos seguintes fragmentos:

Facilita a aprendizagem, a autonomia, cria uma dinâmica de maior participação do aluno. (P2).

Mais próximo das rotinas externas à sala de aula, estímulo à menor hierarquia em decisões de consenso e promove autorreflexão quanto à autonomia do aluno. (P3).

Potencializa o processo de construção coletiva do conhecimento, ressignifica o processo metodológico de ensino-aprendizagem, aproxima os sujeitos do contexto educativo com o conteúdo do mundo tecnológico e prova novas formas de pensar e fazer o movimento da educação como processo social. (P5).

As metodologias ativas promovem maior interação entre professor e aluno e o conhecimento. (P6).

Com base nos relatos dos docentes, percebe-se a relevância do uso das metodologias ativas no processo educativo. Tal afirmação converge para o pensamento dos autores que pesquisam a utilização das metodologias ativas, como Behrens (2007, $2008,2011,2013)$, Moran (2018) e Valente (2018), para os quais as metodologias ativas tornam os estudantes protagonistas de suas aprendizagens, promovendo a construção coletiva do conhecimento, desencadeada pela mudança de paradigma em educação. 
Em relação aos desafios e às dificuldades sobre a utilização de metodologias ativas na educação superior, os professores apontaram o seguinte:

As metodologias devem fazer parte da crença do professor; ele precisa acreditar, estudar e se preparar para o uso dessa abordagem; entretanto, não são todos os professores que estão dispostos a romper com a prática já estabelecida. (P1).

Resistência dos alunos e do professor que possuem uma zona de conforto. (P2).

A predisposição dos estudantes, o compromisso dos professores, o envolvimento das diferentes situações de ensino. (P4).

Compreensão do seu sentido e significado, dificuldade em mudar os paradigmas educacionais; tentar o novo é sempre um processo de insegurança, e isso interfere. Às vezes, a inovação precisa ter ousadia, coragem e compreensão do erro, desafio do tentar, experimentar, entender, compreender antes de registrar, refletir o novo. (P5).

Quebrar o paradigma tradicional para uma educação inovadora e ter um olhar aberto e reflexivo para as práticas pedagógicas, saber aplicar as metodologias que, de fato, contribuam na construção do conhecimento, e não apenas mais uma dinâmica. (P6).

Nos relatos dos professores partícipes da pesquisa, embora estes façam implementação das metodologias ativas no ensino superior, percebe-se que as dificuldades em sua materialidade estão envoltas pela demanda de rever a postura professor/aluno, romper com a zona de conforto, atuar no campo da inovação e da incerteza em sala de aula, compartilhar saberes, ter humildade intelectual e firmar compromisso social e pedagógico com a formação cidadã e humana dos acadêmicos, aspectos que Ujiie (2020) destaca como importantes na formação de professores.

De acordo com Valente (2018), são várias as dificuldades para a implantação das metodologias ativas; mesmo diante disso, o autor ressalta que gradativamente diversas instituições de ensino já estão aderindo a essa perspectiva de ensino, buscando inovar as práticas pedagógicas, visando transformar a educação e as realidades de pertencimento. Nessa dinâmica, temos a articulação cara a Mezzaroba e Carriquiriborde (2020) entre teoria e prática, materializada a partir das metodologias ativas em ação da prática educativa e formativa.

Outra indagação feita aos participantes da pesquisa primou por focalizar quais metodologias ativas eram utilizadas e quais as mais adequadas à sua prática docente. Seguem adiante as respostas: 
Sala de aula invertida, rotação por estações, aprendizagem por pares e design, porque têm processos híbridos em sua essência. (P3).

A sala de aula invertida e a gamificação, pois, quando o estudante tem um conhecimento prévio sobre os conteúdos matemáticos, ele tem uma possibilidade maior de assimilar o que está sendo abordado em sala de aula. Em relação ao uso da gamificação, os estudantes da atualidade têm uma relação estreita com games e jogos. Utilizar essa abordagem em sala de aula poderia fazer com que eles se envolvessem mais com a construção de seu próprio conhecimento. (P4).

Gosto da sala de aula invertida por já ter experimentado o processo de vivências dessas práticas, primeiro como aprendente e depois como alguém na função de propiciar a experiência aos alunos. Tenho observado uma melhora significativa na relação professor/aluno e ensino/aprendizagem. (P5).

De acordo com as respostas dos professores, observa-se que a maioria deles procura utilizar diversas estratégias pautadas nas metodologias ativas em sua prática docente. Foram mencionadas: aprendizagem baseada em problemas, rotação por estações, aprendizagem por pares, sala de aula invertida e gamificação.

Com relação à aprendizagem baseada em problemas, segundo Moran (2018, p. 16), "[...] é uma metodologia de aprendizagem em que alunos se comprometem em uma tarefa por meio de desafios com a finalidade de solucionar um problema ou desenvolver algum projeto que se articule com a vida fora do contexto de sala de aula".

A rotação por estações é uma técnica de ensino híbrido pautada em criar diferentes ambientes dentro da sala de aula e formar uma espécie de circuito, permitindo que os estudantes abordem determinado conteúdo de diferentes maneiras e que realizem manipulação e aquisição de conhecimento transitando em sala de aula nas diferentes estações de conhecimento.

A maioria dos professores indica como estratégia a aprendizagem entre pares, que ocorre em diversos grupos de interesses, podendo acontecer tanto de modo presencial como de forma virtual. Consoante Moran (2018), são grupos que partilham o que sabem, auxiliam nas dúvidas e iluminam as percepções no processo de construção do conhecimento.

A sala de aula invertida, segundo Moran (2018), é uma estratégia ativa que envolve o modelo híbrido, otimizando o tempo da aprendizagem e do professor. Nesse enfoque, no primeiro momento, o conteúdo é acessado nas redes (aula, palestra, texto 
e/ou vídeo) a partir da casa do aluno, e a discussão das dúvidas, questionamentos e reflexões adentram o universo escolar no segundo momento.

Os participantes da pesquisa apontam que também fazem uso da gamificação no espaço-tempo de suas aulas, a partir de simulações e elementos lúdicos. Para Moran (2018), essa prática está cada vez mais presente no cotidiano da escola como uma estratégia que estimula, encanta e motiva a aprendizagem dos alunos.

Diante das estratégias apresentadas pelos sujeitos das pesquisas, tem-se ratificado o que os estudos de Bacich (2018), Behrens (2007) e Moran (2018) vêm afirmando sobre a importância do uso das metodologias ativas, com uma visão complexa ou holística, no sentido de potencializar novas aprendizagens.

A última pergunta girou em torno da seguinte questão: "Como as metodologias ativas podem contribuir para a prática dos professores universitários em seu ponto de vista?". Seguem as respostas:

Para ressignificar as práticas pedagógicas e integrar o aluno nos processos de ensino e aprendizagem; logo, estimulá-lo a aprender com pesquisa e buscar novas alternativas para reconstruir o conhecimento. (P1).

Os professores universitários podem aproveitar essas práticas para motivar os estudantes a desenvolver sua autonomia para a aprendizagem e também podem aproveitar para aprofundar mais os conteúdos que estão sendo abordados. (P2).

Contribuem, a meu ver, em três grandes blocos: 1) metodologia, forma de ensinar; 2) relações de aprendizagem entre professor e aluno; e 3) acesso ao conhecimento. Metodologia, por mexer nas estruturas do processo e aprendizagem; no entanto, ela acontece nas relações de envolvimento com a dinâmica do ensinar e do aprender, modifica, reestrutura e reconfigura o modo de se pensar e fazer a aprendizagem. (P4).

Modifica e amplia as condições relacionais entre os sujeitos, professor e aluno, mobilizando uma relação mais dinâmica, pautada no movimento do conhecimento. (P5).

As concepções dos professores universitários convergem para o pensamento de Moran (2018) de que as metodologias contribuem para a participação efetiva dos discentes como protagonistas de suas aprendizagens, uma vez que, ao fazer uso dessa abordagem de ensino, os professores têm a possibilidade de ressignificar suas práticas pedagógicas, como estão bem explicitadas nas falas dos que participaram deste estudo. 


\section{Considerações finais}

Com base no referencial teórico e a partir dos resultados debatidos, pode-se concluir que as metodologias ativas contribuem para a aprendizagem dos alunos, estimulando neles diversas maneiras de aprender, promovendo sua autorreflexão e autonomia, além de possibilitar a construção coletiva do conhecimento. Observou-se que a metodologia ativa faz parte da prática desses professores e que são várias as estratégias utilizadas por eles que podem favorecer 0 desenvolvimento da aprendizagem.

No que se refere aos desafios e às dificuldades sobre a utilização de metodologias ativas no ensino superior, percebeu-se que foi apontada certa resistência tanto por parte de alguns professores quanto por parte de alguns alunos. Isso pode significar a necessidade de superar o paradigma tradicional, indo em direção a uma educação inovadora, complexa ou holística. Assim, tal compreensão leva a inferir que essa resistência pode também estar relacionada aos sentidos e aos significados das metodologias ativas na prática docente e nas aprendizagens dos educandos, denotando a falta de uma formação mais especializada sobre as metodologias ativas, de maior discussão e popularização de sua aplicabilidade.

Ao serem questionados sobre a contribuição das metodologias ativas para a prática dos docentes universitários, constatou-se um consenso entre os profissionais, tendo em vista que, para este grupo que participou da pesquisa, as metodologias contribuem para deixar as aulas mais dinâmicas e contextualizadas.

Observou-se que os sujeitos investigados utilizam diferentes estratégias, que levam em conta os subsídios teóricos da metodologia ativa. Isso denota a diversidade e a pluralidade de ações, de modo a ressignificar a prática na sala de aula.

A utilização da metodologia ativa é um tema que precisa ser ainda mais bem explorado, pois é uma temática envolvente e que rompe com o ensino tradicional, ainda presente em muitos contextos escolares e universitários. Desse modo, o professor precisa integrar metodologias ativas que criem oportunidades para a construção significativa de conhecimento, não sendo apenas um transmissor de conteúdos desconexos e sem utilidade para o estudante. 
Frente a essa exposição, considera-se oportuna a realização de novas pesquisas que discutam a compreensão dos professores da educação básica acerca do uso das metodologias ativas em suas práticas de sala de aula a fim de disseminar e popularizar a temática.

\section{Referências}

BACICH, L. Formação continuada de professores para o uso de metodologias ativas. In: MORAN, J.; BACICH, L. (org.). Metodologias ativas para uma construção inovadora: uma abordagem teórico-prática. Porto Alegre: Penso, 2018. p. 1-25.

BACICH, L.; MORAN, J. M. Metodologias ativas para uma educação inovadora: uma abordagem teórico-prática. Porto Alegre: Penso, 2018.

BEHRENS, M. A. Metodologia de projetos: aprender e ensinar para a produção do conhecimento numa visão complexa. In: TORRES, P. L. (org.). Complexidade: redes e conexões na produção do conhecimento. Curitiba: Senar, 2014. p. 95-116.

BEHRENS, M. A. O paradigma da complexidade na formação e no desenvolvimento profissional de professores universitários. Revista de Educação, Porto Alegre, v. 30, n. 3, p. 439-455, 2007.

BEHRENS, M. A. O paradigma emergente e a prática pedagógica. Petrópolis: Vozes, 2013.

BEHRENS, M. A. Paradigma da complexidade: metodologia de projetos, contratos didáticos e portfólios. Petrópolis: Vozes, 2006.

BEHRENS, M. A. Paradigma da complexidade: metodologias, projetos, contratos didáticos e portfólios. 2. ed. Petrópolis: Vozes, 2008.

BEHRENS, M. A. Projetos de aprendizagem colaborativa num paradigma emergente. In: MASETTO, M.; MORAN, J. M.; BEHRENS, M. A. (org.). Novas tecnologias e mediação pedagógica. 19. ed. Petrópolis: Papirus, 2011. p. 67-132.

BEHRENS, M. A.; PRIGOL, E. L. Prática docente: das teorias críticas à teoria da complexidade. In: SÁ, R. A.; BEHRENS, M. A. (org.). Teoria da complexidade: contribuições epistemológicas e metodológicas para uma pedagogia complexa. Curitiba: Appris, 2019. p. 65-85.

BOGDAN, R.; BIKLEN, S. K. Investigação qualitativa em educação: uma introdução à teoria e aos métodos. Porto: Porto, 1994. 
CAPRA, F. A teia da vida: uma nova compreensão científica dos sistemas vivos. São Paulo: Cultrix, 2006.

JUNGES, F. C.; KETZER, C. M.; OLIVEIRA, V. M. A. Formação continuada de professores: saberes ressignificados e práticas docentes transformadoras. Revista Educação \& Formação, Fortaleza, v. 3, n. 9, p. 88-101, 2018.

LÜDKE, M.; ANDRÉ, M. Pesquisa em educação: abordagens qualitativas. 2. ed. São Paulo: EPU, 2013.

MASETTO, M. T. Competência pedagógica do professor universitário. São Paulo: Summus, 2006.

MASETTO, M. T. (org.). Docência na universidade. 3. ed. Campinas: Papirus, 1998.

MASETTO, M. T. Mediação pedagógica e o uso da tecnologia. In: MASETTO, M. T.; MORAN, J.; BEHRENS, M. A. (org.). Novas tecnologias e mediação pedagógica. 19. ed. Petrópolis: Papirus, 2011. p. 133-182.

MEZZAROBA, C.; CARRIQUIRIBORDE, N. Teoria e prática: questões imprescindíveis à prática educativa. Revista Educação \& Formação, Fortaleza, v. 5, n. 3, p. e2807, 2020.

MORAES, M. C. Pensamento eco-sistêmico: educação, aprendizagem e cidadania no século XXI. Petrópolis: Vozes, 2004.

MORAN, J. M. Ensino e aprendizagem inovadores com apoio de tecnologias. In: MASETTO, M. (org.). Novas tecnologias e mediação pedagógica. 21. ed. São Paulo: Papirus, 2013. p. 11-73.

MORAN, J. M. Metodologias ativas para uma aprendizagem mais profunda. In: MORAN, J. M.; BACICH, L. (org.). Metodologias ativas para uma construção inovadora: uma abordagem teórico-prática. Porto Alegre: Penso, 2018. p. 1-25.

MORAN, J. M. Mudando a educação com metodologias ativas. In: SOUZA, C. A.; MORALES, O. E. T. (org.). Convergências midiáticas, educação e cidadania: aproximações jovens. Ponta Grossa: UEPG/Proex, 2015. p. 15-33.

MORIN, E. Os sete saberes necessários à educação do futuro. 3. ed. São Paulo: Cortez, 2001.

MORORÓ, L. P. A influência da formação continuada na prática docente. Revista Educação \& Formação, Fortaleza, v. 2, n. 4, p. 36-51, 2017.

SENNA, C. M. P. et al. Metodologias ativas de aprendizagem: elaboração de roteiros de estudos em "salas sem paredes". In: MORAN, J. M.; BACICH, L. (org.). Metodologias ativas para uma construção inovadora: uma abordagem teórico-prática. Porto Alegre: Penso, 2018. p. 220- 237. 
Editora responsável: Lia Machado Fiuza Fialho Pareceristas ad hoc: Carmem Rolim e Juares Thiesen

Como citar este artigo (ABNT):

BLASZKO, Caroline Elizabel; CLARO, Ana Lúcia de Araújo; UJIIE, Nájela Tavares. A contribuição das metodologias ativas para a prática pedagógica dos professores universitários. Educ. Form., Fortaleza, v. 6, n. 2, e3908, 2021. Disponível em:

https://revistas.uece.br/index.php/redufor/article/view/3908

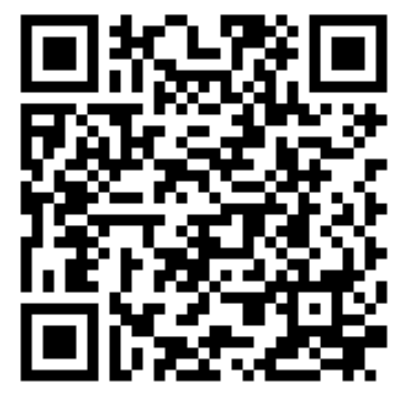

Recebido em 1을 de setembro de 2020.

Aceito em 16 de janeiro de 2021.

Publicado em 20 de fevereiro de 2021. 